\title{
NEW YORK NEUROLOGICAL SOCIETY.
}

Jan. 8, 1907.

The President, Dr. Joseph Fraenkel, in the Chair.

DEMONSTRATION OF THE RESULTS OF THE RE-EDUCATIONAL TREATMENT OF TABES DORSALIS.

By Dr. H. S. Frenkel, of Heiden, Switzerland.

Dr. Frenkel said that in order to complete his theoretical explanations of the re-educational treatment in tabes dorsalis, he had tried to get some demonstrable results by starting the treatment in a few hospital cases of different stages of ataxia. Through the kindness of the President of the New York Neurological Society, Dr. Joseph Fraenkel, he was able to show three different cases of tabic ataxia treated in the Montefiore Home, with the most attentive and intelligent assistance of Dr. E. A. Fruchthandler, the assistant physician of the Home. Whilc the results in these three cases were perhaps not striking, on account of the short duration of the treatment and the nature of the cases, they demonstrated very well some important improvements, and also the lincs to be followed in the further treatment.

The first patient was a man, sixty-two years old, whose present illness began seven and a half ycars ago, when he noticed pain of gradually increasing severity and of a shooting character in both legs. This was diagnosed as sciatica. At the cnd of two years he could not walk in the dark, and for the past two and a half ycars he could not walk without a cane. The interest in this case, Dr. Frenkel said, lay in the marked hypotonia, which was almost limited to the left knee. An examination showed that the difficulty of the gait was due not so much to the ataxia as to the hypotonia, and its unequal development in the knces. This change rendered these patients cspccially tunfit to balance the weight of the body. In unilateral hypotonia the act of walking' was rendered more harmful than in a case of equal knee-hypotonia, as in the former condition the patient was inclined to rcst the weight of the body on the hypotonic side. By doing this, the concavity grew more and more, and the re-educational treatment, as ordinarily applied, not only failed in its purpose, but was directly dangerous and actually contra-indicated. The proper procedure in these cases was to have a special appliance made before the re-educational treatment was instituted. The principle of the appliance was very simple, but its execution was rather difficult. A marked improvement in the gait of this patient was noticed when he wore the appliance.

The second patient showed by Dr. Frenkel was a man, forty-three years old, who showed all the classical symptoms of tabes dorsalis. His history dated back six years. In 1904 he was first unable to walk in the dark, and since then he had been compelled to use a cane. His gait had improved markedly under the re-educational method of treatment. He was able to walk without the aid of a cane, and in the course of four or six weeks, the speaker said, he would probably be able to walk in the dark.

The third case shown by Dr. Frenkel was a man, forty-nine years old, who had suffered from tabes since 1900 , and for the past five years he had been confined either to bed or to a chair. On Nov. Io, Ig06, when Dr. 
Frenkel first saw him, the ataxia was very marked. In order to raise him from his chair it required the assistance of two nurses, and when he attempted to remain on his feet his knees would give way under him and he would fall to the ground. Treatment was begun on the following day. At first, the patient was able to stand only for a second or two; then the period gradually lengthened, and on Dee. II, he stood without assistance for two minutes and ten seconds. Three days later he arose from his chair without assistance, and balaneed himself for a few seconds without falling. On Dec. 25, he was able to lift his foot and put it down without falling. He was now able to take a few steps, and there was a slow but gradual improvement in his condition.

In conclusion, Dr. Frenkel again emplasized the fact that this method of re-education applied without a thorough knowledge of its principles and dangers was criminal.

Dr. Georgte W. Jacoby said that in connection with the appliance shown by Dr. Frenkel he wished to call attention to the fact that within the past few years a relative of the ortlopedist Hessing had settled in this comntry, and the high standaro of the work he turned out was worthy of the appreciation of the profession. For example, in order to obtain an exact fit, it was his plan to build his apparatus upon a model of the part.

Dr. Jacoby saicl he could not let this opportunity pass without expressing his appreciation of the work done by Dr. Frenkel since his arrival in this country. While the progress made by the patients shown at this meeting was apparently not very startling, they certainly showed marked improvement, which could be appreciated by those who had been able to watch these cases from the time when treatment was first commenced.

Dr. Frenkel, in closing, said that while Hessing made some very wonderful appliances, they were intended for orthopedic rather than for neurological conditions.

In reply to a question as to whether these excrcises increased the tabetic pains, the speaker said that on the contrary, some of the patients took them in order to relieve the pains.

Dr. Frenkel said that he agreed with Dr. Jacoby that while the improvement in the cases he had shown was not startling. still they furnished a good example of what might be expected from this re-educational method of treatment. In the third case. for example, the patient had not been able to stand for five years, and now, within a period of less than two months, he was able to stand and even to lift his foot. Standing was the first essential in these cases; the treatment of walking was sceondary. People who could learn to stand could always learn to walk, but you could not teach a man to walk who was unable to stand. A far advanced case of this kind, therefore, was a more instructive object lesson than it would be to show a score of milder eases whose locomotion had been improved by this method.

\section{A CASE OF SUBCORTICAL CYST: OPERATION AND RESULT.}

By Dr. William M. Leszynsky.

The patient was a school girl, twelve years old, who was referred to him on April 24, 1905, by Dr. Francis Todd, of Paterson, N. J., with the following history: For the previous five months she had often stumbled while walking, and had occasional jerking of the left hand and arm, frequently dropping things held in that hand. She was supposed to have chorea. Two months ago, when she eame under Dr. Todd's care, she complained of occasional general headache and twitehing of the fingers 